Cuadernos de Filología Clásica. Estudios Latinos

ISSN: 1131-9062

http://dx.doi.org/10.5209/CFCL.57808

\title{
Tradición y modernidad en el De constructione octo partium orationis (México, 1579) de Manuel Álvares, S.I ${ }^{1}$.
}

\author{
Juan María Gómez Gómez²
}

Recibido: 21 de febrero de 2016 / Aceptado: 10 de septiembre de 2017

Resumen. El De constructione octo partium orationis publicado en México en 1579 es una de las muchas ediciones de la Sintaxis del jesuita portugués Manuel Álvares; una edición que presenta interesantes novedades con respecto a las anteriores ediciones de la misma obra. El propósito de este trabajo es presentar y valorar estas innovaciones en el contexto de la pedagogía jesuita y en el marco doctrinal de la gramática latina del siglo XVI en Europa y en Nueva España. Con ello, se pretende contribuir al conocimiento de la enseñanza del latín por parte de los jesuitas en el Nuevo Mundo.

Palabras clave: Manuel Álvares; gramáticas jesuitas; sintaxis latina; enseñanza de la gramática; copia uerborum; versos mnemotécnicos.

\section{[en] Tradition and modernity in De constructione octo partium orationis (Mexico, 1579) by Manuel Álvares, S.I.}

Abstract. De constructione octo partium orationis published in Mexico in 1579 is one of the numer-
ous editions of the Syntax written by the Portuguese Jesuit Manuel Álvares. This is an edition which
presents interesting novelties regarding previous editions of the same work. The purpose of this article
is to present and value these innovations within the context of the Jesuit Pedagogy and the doctrinal
frame of the Latin grammar from the $16^{\text {th }}$ century in Europe and New Spain. Therefore, it is expected to
contribute to the knowledge of the teaching of Latin by Jesuits in the New World. Keywords: Manuel Álvares; Jesuit grammars; Latin syntax; grammar teaching; copia uerborum; mnemonic verses.

Sumario. 1. Introducción. 2. Estructura y contenidos del volumen de la edición mexicana de 1579. 3. El De constructione octo partium orationis en la edición mexicana. 4. Omisiones y adiciones resaltadas en el prólogo. 4.1 Omisión de escolios. 4.2 Adición de la Sintaxis figurada. 4.3. Inclusión sistemática de versos mnemotécnicos. 5. Conclusión. 6. Referencias bibliográficas.

$1 \quad$ Este trabajo se ha realizado en el marco del proyecto de investigación «Gramáticas en Europa (ss. XVII-XVIII). Estudios y ediciones» (FFI2016-78496-P), financiado por el Ministerio de Economía, Industria y Competitividad, dirigido por los profesores E. Sánchez Salor y M. ${ }^{a}$ Luisa Harto Trujillo y englobado en el Grupo de Investigación «Las artes de la palabra de la Antigüedad al Renacimiento» (HUM 002), financiado por la Junta de Extremadura y dirigido por el profesor E. Sánchez Salor. Al mismo quiero agradecer las sugerencias formuladas para el presente trabajo. Este agradecimiento se extiende a los revisores del trabajo por sus pertinentes correcciones.

$2 \quad$ Universidad de Extremadura. Dpto. de Ciencias de la Antigüedad. Email: juanmgg@unex.es. 
Cómo citar: Gómoez Gómez, J. M., «Tradición y modernidad en el De constructione octo partium orationis (México, 1579) de Manuel Álvares, S.I», Cuad. Filol. Clás. Estud. Lat. 37.2 (2017), 317-334.

\section{Introducción}

Como es bien sabido, la enseñanza del latín en Nueva España -en la línea del resto del nuevo continente- estuvo desde el principio en manos de las órdenes religiosas, primero franciscanos, dominicos y agustinos, y después, a partir de 1572, también de los jesuitas. También es sabido que en el Nuevo Mundo y, concretamente, en Nueva España -como en Europa-, el conocimiento del latín era la base para la educación superior y, por tanto, un importante medio de ascenso en la escala social. Para su enseñanza, estos clérigos-maestros trasladaron allí los métodos y manuales de enseñanza conocidos en Europa, adaptándolos en mayor o menor medida a la idiosincrasia de los nuevos discentes ${ }^{3}$.

Concretamente, por lo que se refiere a los jesuitas, exportaron al Colegio de San Pedro y San Pablo ${ }^{4}$, en México, de la mano del padre Lanuchi (1575) el método del Colegio Romano, que, basado en el del Colegio de Mesina y heredado a su vez de la Universidad de París, se fundamentaba, entre otros aspectos, en la atención individualizada al alumno, al que se exigía unos sólidos fundamentos de gramática latina, lo cual se conseguía con constantes ejercicios de memoria, repeticiones, concertaciones, composiciones en prosa y en verso, declamaciones, etc., esto es, una ejercitación constante que les enseñara a expresarse con corrección, fluidez y elegancia en lengua latina ${ }^{5}$.

Para ello, primero echaron mano de gramáticas, retóricas, poéticas, vocabularios y ediciones de los clásicos grecolatinos editados en el viejo continente. Desde Europa llegaron las Introductiones Latinae y vocabularios de Nebrija -originales o reformas y comentarios de Juan Luis de la Cerda o de Diego López-, de Erasmo, de Despauterio, de Luis Vives, de Cipriano Suárez, y, por supuesto, la Gramática del jesuita Manuel Álvares, entre otros muchos manuales (Osorio 1979 y 1980).

También comenzaron a editarse en Nueva España manuales originales para estudio del latín aprovechando e incorporando la tradición humanística europea. La Gramática del franciscano Maturino Gilberti fue la primera gramática latina impresa en el Nuevo Mundo (1559) y entre las más destacadas 6 . Esta incorporará un capítulo de elegancias ${ }^{7}$-concretamente el séptimo- procedente de Erasmo y otros autores y titulado Septima pars, quaedam pro pueris linguae Latinae, salutandi, ualedicendi, percunctandi, exercitamenta ac formulae ex Erasmo Roderodamo aliisue doctissimis (Osorio 1980, 129; 1984, 167-179). Además, se reeditaron con adaptaciones al-

Cf., al respecto, Osorio (1979, 1980, 1984, 1990, esp. XI-LVII), Gonzalbo (1989), Pérez (2009) y Valencia (2015).

4 Precisamente en el Colegio de San Pedro y San Pablo instalaría su taller el impresor de la edición aquí estudiada, Antonio Ricardo, al llegar a México. Cf. Fernández (1994, 474).

$5 \quad C f$. Gómez (1954, 55-64). Sobre el modus parisiensis en los colegios de la Compañía de Jesús, $c f$. Codina (1968).

6 Lleva como título Grammatica Maturini. Tractatus omnium fere quae Grammatices studiosis tradi solent a fratre Maturino Gilberto minorita ex doctissimis collectus auctoribus. Hay edición moderna con introducción, traducción y notas a cargo de Rosa Lucas (2003).

Sobre los capítulos de elegancias y de copia en las gramáticas latinas, cf. Sánchez (2002 y 2012). 
gunas de las obras gramaticales más famosas y extendidas por Europa, como sucedió con la Gramática de Manuel Álvares (Osorio 1980, 133-145).

Precisamente, en cuanto a la Gramática de Álvares, también es conocido que desde que el De constructione octo partium orationis del jesuita Manuel Álvares se editara dos veces en Venecia, en 1570 y en $1571^{8}$, y un año más tarde, en 1572 , en Lisboa, la editio princeps de la Gramática completa, De institutione grammatica libri tres ${ }^{9}$, con el primer libro dedicado a la Morfología, el segundo a la Sintaxis -lo que había sido el De constructione octo partium orationis - y el tercero a la Prosodia y la Métrica, se fueron realizando ediciones totales de esta obra, con los tres libros, y parciales, solo de alguno de ellos, hasta llegar en la actualidad a más de $750^{10}$. Tanto las parciales como las de la Gramática completa pueden agruparse en ediciones o artes maiores y minores (Kemmler 2013, 46). En las primeras, amplios escolios explicativos acompañan a los preceptos generales y están destinadas fundamentalmente a los maestros - por ejemplo, el De constructione octo partium orationis (Venecia 1571 y Sevilla $1573^{11}$ ) o la editio princeps lisboeta (1572), entre otras muchas-; las segundas, en cambio, recogen básicamente el texto de los preceptos generales, sin apenas escolios, y están destinadas a los alumnos -por ejemplo, el De constructione octo partium orationis (Venecia 1570), o las ediciones de los De institutione grammatica libri tres realizadas en Lisboa en $1573^{12}$ y en $1578^{13}$, por citar solo algunas.

Pues bien, dentro de esta doble división, la edición que nos ocupa del De constructione octo partium orationis (México $1579^{14}$ ) sería parcial, por tratarse solo del libro destinado a la Sintaxis, y minor, por contener básicamente solo los preceptos generales. Se trata de una edición en la que se combinan recursos de raigambre medieval (versos mnemotécnicos) para la memorización de la sintaxis, con otros elementos de mayor modernidad, tales como las figuras de construcción, que ya se hallaban en la primera edición completa de la Gramática de Álvares, pero no así en las ediciones primeras del De constructione octo partium orationis (Venecia $1570 \mathrm{y}$ 1571, o Sevilla 1573). Volveremos sobre ello más adelante.

Años más tarde aparecería editada en México también la obra completa de Álvares, De institutione grammatica libri tres, en 1594 (Osorio 1980, 141-145) ${ }^{15}$, lo que demuestra la importancia de esta obra en Nueva España.

8 Realmente, la edición de 1570 lleva en su portada fecha de 1571, pero 1570 en el colofón. A partir de ahora aparecerán como Venecia 1570 y Venecia 1571 respectivamente. Agradezco al profesor Rolf Kemmler el facilitarme el ejemplar de la primera edición veneciana. Sobre estas primeras ediciones de la Gramática de Álvares, cf. Springhetti (1962, 286-8) y Ponce de León (2004).

$9 \quad$ A partir de ahora aparecerá como Lisboa 1572.

10 En la actualidad, el Catálogo LUDOSAT registra alrededor de 650 ediciones (entre ediciones parciales y totales), pero el profesor Kemmler nos ha facilitado una actualización manuscrita de este catálogo donde aparecen 766 - contando también vocabularios derivados de la Gramática de Álvares-, a las que habría que añadir dos ediciones críticas más recientes: una de la Gramática completa y con escolios (Ponce de León 2002), y otra del libro segundo (la Sintaxis), también con escolios explicativos, con traducción al español (Gómez 2003).

11 A partir de ahora aparecerá como Sevilla 1573.

12 Para un estudio de esta, $c f$. Kemmler (2013).

13 A partir de ahora aparecerán como Lisboa 1573 y Lisboa 1578 respectivamente.

14 A partir de ahora aparecerá como México 1579.

15 Comenta aquí I. Osorio que el libro segundo de esta edición lleva una portada individual con fecha de 1595; también, que hay noticia de una edición completa de la Gramática de Álvares en México, en la imprenta de Antonio Ricardo, en 1584, de cuya existencia duda. En el catálogo LUSODAT pueden verse consignadas otras ediciones mexicanas posteriores. 
Según nos transmite también I. Osorio (1979, 24-25), el general de la Compañía, Everardo Mercuriano, habría instado, en una carta de 12 de marzo de 1576, al provincial, Pedro Sánchez, a proveerse de los libros necesarios para la correcta impartición de su ministerio, y recomendaba, entre otros, la gramática de Álvares:

Entendemos hay en el colegio de México harto gran falta de libros; la cual no es pequeña; y será de aquí adelante aun mayor, si no se provee con tiempo; porque, en fin, sin libros, muchos y buenos, no se pueden hacer los más ministerios de nuestra Compañía. Por eso deseo mucho, V.R. provea en esto con toda la diligencia que le fuere posible; y parece que el medio más a propósito será, que envié una buena suma de dineros al padre procurador de las Indias, en Sevilla, con la lista de los libros que fueren necesarios; el cual les hará proveer de Amberes, de todo lo necesario, con mucha comodidad, y entre otros, de una gramática del padre [Manuel] Álvares, y de la filosofía del padre Toledo; los cuales, según entiendo, será muy bien se leyesen por allá.

Teniendo en cuenta todo lo dicho, este trabajo se presenta dividido en dos partes. En primer lugar, se describirán de forma general los contenidos del volumen en el que se encuentra el De constructione octo partium orationis. A continuación, nos centraremos en la edición de este tratado sintáctico, para, a partir del prólogo y del comienzo mismo de los preceptos, mostrar y valorar, dentro del marco doctrinal y pedagógico de gramática latina en Europa y Nueva España, las concomitancias y, sobre todo, las divergencias y novedades que presenta esta edición con respecto a las anteriores del texto, en especial con respecto a las venecianas de 1570 y 1571 y la sevillana de 1573, pero también con relación a la editio princeps de la Gramática completa (Lisboa, 1572) y sus derivadas abreviadas -solo con los preceptos-, de Lisboa (1573 y 1578).

\section{Estructura y contenidos del volumen de la edición mexicana de $\mathbf{1 5 7 9}$}

Esta edición del De constructione octo partium orationis, la Sintaxis de Álvares, es la primera de la que tenemos constancia impresa en Nueva España. De ella habían dado noticia, entre otros, N. León (1887), C. Sommervogel (1890, t. I, col. 225), Medina (1989 [fasc. 1912], t. 1, 236-7), Palau y Dulcet (1948, t. 1, 9343) o I. Osorio $(1980,133)^{16}$. En la actualidad existe una copia digital a partir de un ejemplar de la Universidad de Texas, que es la que utilizamos en este trabajo. La descripción del tratado sintáctico de Álvares que ofrece J. T. Medina ${ }^{17}$ coincide plenamente con la de

16 De I. Osorio, en concreto, tomamos la referencia de Nicolás León que ofrecemos.

17 De / constrv/ ctione octo / partium orationis. / P. Emanuelis Alvari Lusitani e Societate /Iesv. / Estampeta con un IHS radiante dentro de un óvalo, con la leyenda: VOCARIS NOMEN EIVS IESVM; y por los costados de afuera esta otra: DVLCE TVVM NOSTRO / DEFIGAS PECTORE NOMEN/ NAMQVE. TVO CONSTAT / NOMINE NOSTRA SALVS / MEXICI. / Cum Licentia, Apud Antonium Ricardum. Anno / M. D.LXXIX.

$8^{\circ}$ - Port. - v. en bl. - Advertencia Ad tyrones, recto de la primera hoja, a cuyo verso empieza el texto, foliado 3-56, en cuyo frente termina con el LAVS DEO; a la vuelta sigue Sintaxis / R. P. Emanvelis Al / vari Societatis Iesv. Carmine breui / ter collecta; y concluye en la hoja 60 - Foliado A-H, de 8 hojas, menos el último, que es de 4. - Letra Romana à 28 líneas por página. 
la primera parte del volumen manejado; pero en este se añaden unos anexos, todos ellos relacionados también con la enseñanza de la gramática latina.

Así, los 60 primeros folios, en $8^{\circ}$, paginados en el recto y con signatura A2 a partir del prólogo, contienen la portada con el emblema de la Compañía de Jesús, el prólogo (Ad tirones, f. $2 \mathrm{r}^{\circ}$ ), la Sintaxis de Álvares sin los escolios explicativos (ff. $2 \mathrm{v}^{\circ}-56 \mathrm{r}^{\circ}$ ) pero con hexámetros mnemotécnicos que encabezan cada uno de los preceptos-salvo las excepciones que veremos- $\mathrm{y}$ concluyendo con la recopilación de esos hexámetros mnemotécnicos de seguido (ff. $56 \mathrm{v}^{\circ}-60 \mathrm{v}^{\circ}$, que acaban en la signatura $\left.\mathrm{H} 4 \mathrm{v}^{\circ}\right)$.

A continuación, en el volumen aparece un nuevo cuadernillo, sin paginación y con signatura nueva, que parte de A2, lo que indicaría que el impresor consideraba que podía incluirse bajo la portada primera. Se trata de 15 folios $\left(\mathrm{r}^{\mathrm{o}}-\mathrm{v}^{\mathrm{o}}\right)$ con construcciones frecuentes y elegantes de diferentes nombres -adjetivos en este caso- y verbos, con su respectiva traducción al español, es decir, de un capítulo de Copia uerborum. Este tipo de capítulos será, desde finales del XVI y durante todo el XVII, frecuente en las gramáticas compuestas por jesuitas ${ }^{18}$. Por citar solo algunas de las más destacadas, se incluye un capítulo de Copia en la Sintaxis de Bartolomé Bravo ${ }^{19}$ (Ponce de León 2003, 574; Espino 2005, 228; Sánchez 2012, 86 ss.), o en la Reforma de las Introductiones Latinae de Nebrija a cargo de Juan Luis De la Cerda ${ }^{20}$, al menos a partir de su edición de 1629 (Sánchez 2012, 96-116; Gómez 2013, XXXI-XXXIII). Pero, antes que en estas, también se había incorporado un capítulo de copia en la edición madrileña de 1593 del De constructione octo partium de Manuel Álvares ${ }^{21}$, de lo que ya dio noticia J. Espino $(2005,228)$. Pues bien, antes aún se incorpora este capítulo en nuestra edición novohispana.

En efecto, se recogen construcciones diversas y frecuentes de adjetivos y verbos -por separado- que ya se han referido en los preceptos sintácticos de forma general, pero que ahora se desarrollan más de cara a su memorización y a su utilización en el día a día. Se distribuyen adjetivos y verbos según el o los casos con que pueden construirse. Por ejemplo, dentro de la construcción de adjetivos con genitivo: "Gnarus. a. m. 'Que entiende', o 'conosce' Reipub <licae $>$ Cic. Ignarus. a. m. 'Ignorante', o 'que no sabe', Philosophiae. Cic. ${ }^{22}$ " (f. A2r ${ }^{\circ}$ ). También los hay que pueden construirse con más de un caso, como por ejemplo: "Expers, tis. 'El que carece', o 'no tiene'. Omnis eruditionis. Cic. Metu ${ }^{23}$. Plau., Sal." (f. A2 $\mathrm{v}^{0}$ ). En ocasiones, el caso varía dependiendo del significado que tenga el verbo, como, por ejemplo, en la construcción del verbo neutro:

\section{De constructione uerbi neutri}

Sum, es, fui amat genetium $<$ sic $>$ cum significat possesionem, aut ad aliquid pertinere, exceptis meum, tuum, suum, nostrum, uestrum. Sum pro habeo, datiuum.

\footnotetext{
18 Para un estudio de los capítulos sobre la copia en los tratados de jesuitas y su importancia en Europa desde finales del siglo XVI y durante el XVII, $c f$. Sánchez (2012, esp. 67-122 y 214-257) y Espino (2005).

19 La primera edición del Liber de octo partium orationis constructione de Bravo data de 1600 (Medina del Campo).

20 La primera edición del Arte Reformada de Nebrija a cargo de Juan Luis de la Cerda, la que se convertiría en el Arte Regia, data de 1601, pero esta edición no contenía el capítulo de copia; no encontramos este capítulo, entre las ediciones que conocemos, hasta la de 1629.

21 En efecto, a partir del f. 69r ${ }^{\circ}$ encontramos: Copia nominum et uerborum. (Madrid 1593).

22 En este y en los siguientes textos de la edición reproducimos la grafía de la misma.

23 Expers -tis puede construirse con genitivo (omnis eruditionis) o con ablativo (metu).
} 
Sum pro afficio, duos datiuos. Sum dum refertur ad laudem $<$ ue $>1$ uituperationem, ablatiuum, et interdum genitiuum. Sum pro ualeo, ablatiuum [...] (ff. A5v $\mathrm{v}^{\mathrm{o}} \mathrm{A} 6 \mathrm{r}^{\mathrm{o}}$ ).

A veces también, principalmente en el caso de los verbos, se ordenan alfabéticamente, como sucede con los verbos neutros que exigen ablativo (ff. $A 8 v^{\circ}-A 9 r^{\circ}$ ) o con los verbos neutros que se construyen solo con dativo (ff. A10r ${ }^{\circ}-A 11 v^{\circ}$ ). En la mayoría de las ocasiones, como hemos visto, se proporciona la traducción castellana, de manera que los alumnos puedan aprender mejor la forma de utilizar estas construcciones, y, además, se deja constancia de la autoridad clásica que las utiliza, que, con mucha frecuencia, es Cicerón.

Como sucede con la recopilación de los hexámetros mnemotécnicos, estamos ante el método de repeticiones tan propio de la pedagogía jesuita para ejercitar y asentar los conceptos. Habría que adelantar, pues, la inclusión de este capítulo de copia vinculado a la Sintaxis de Álvares a esta edición mexicana. En este aspecto, sería, pues, novedosa esta edición con respecto a las anteriores.

Así mismo, creemos que resulta pertinente dejar claro que se trata de construcciones de adjetivos y verbos derivadas del texto del propio Álvares, a diferencia de lo que se ha dicho al comienzo del trabajo que sucedía con la Gramática del franciscano Maturino Gilberti, que introducía un capítulo de elegancias -concretamente el séptimo-, pero un capítulo derivado de Erasmo y otros autores, no de la propia Gramática en que se incluye. Parece evidente que los jesuitas mexicanos querían diferenciarse en este aspecto de la gramática franciscana. Pero de ello nos ocuparemos en otro lugar.

En el volumen aparecen a continuación, ya sin paginar y sin signatura, una serie de folios con los siguientes contenidos. Un folio $\left(\mathrm{r}^{\mathrm{o}}-\mathrm{v}^{\mathrm{o}}\right)$ con unos breves y confusos ejemplos sobre la forma de las letras mayúsculas y minúsculas, también del diptongo ae, y con cuatro breves normas sobre el comienzo de palabra y renglón (no puede haber dos consonantes iguales); sobre el final del renglón (debe quedar acabada la sílaba), sobre la importancia de atender a las palabras compuestas, para ver si pueden contener consonantes geminadas, y sobre la utilización del punto y la coma. Dos folios y una cara del siguiente con los adverbios locativos y de dirección que se utilizan para preguntar (ubi, unde, quo, qua, quorsum), con los verbos que se usan y con los nombres y casos en que se debe responder; todo ello con la traducción española. Dos folios $\left(\mathrm{r}^{\mathrm{o}} \mathrm{y} \mathrm{v}^{\mathrm{o}}\right)$ con los números cardinales, ordinales y distributivos. Poco más de medio folio (una cara) con el sistema de formación de comparativos y superlativos (en español). Por último, un folio con los verbos que se construyen normalmente con proposiciones completivas bien de infinitivo bien introducidas por conjunciones, también redactado en español aunque con ejemplos del latín ${ }^{24}$.

En definitiva, se trata de unos apéndices, incluida la Copia uerborum, cuya pretensión evidente es completar una guía tanto para comprender la lengua latina como para componer y expresarse en un latín correcto y elegante; un método dirigido básicamente a los alumnos y carente, por tanto, de la abundancia de escolios explicativos que acompañaban a los preceptos generales en otras ediciones anteriores, parciales y totales, de la Gramática de Álvares.

24 Como mero detalle añadimos que precede a la portada una página impresa desgajada de un tratado de prosodia y que lo cierra otra manuscrita con 5 refranes traducidos del latín al español también desgajada de una lista mayor. 
Nos centraremos a continuación en los sesenta primeros folios, esto es, en la parte que reproduce la Sintaxis de Álvares, para comprobar cómo procede el editor de la misma.

\section{El De constructione octo partium orationis en la edición mexicana}

Como ya hemos adelantado, con esta edición del De constructione octo partium orationis sucedía en Nueva España lo mismo que estaba sucediendo en Europa: se editaba la Sintaxis individualmente, respondiendo así a la tradición textual de las sintaxis alvaresianas individuales editadas en Italia (Venecia 1570 y 1571, Roma 1577) y en España (Sevilla 1573) al menos hasta el año $1577^{25}$. Además de responder estas ediciones europeas a un estadio de redacción anterior al del libro segundo de la Gramática completa (Lisboa 1572), su principal común denominador para el objetivo de este trabajo es la ausencia de la Sintaxis figurada (Ponce de León 2004, 274); y ello a pesar de que se anuncie en ellas que hay dos tipos de sintaxis, transitiva e intransitiva, que una y otra se divide en iusta y figurata y que de la figurata se tratará más por extenso al final del libro. En las tres ediciones con explicaciones (Venecia 1571, Sevilla 1573 y Roma 1577), aparece esta doble estructuración de la Sintaxis, como también aparece en el primer escolio del libro segundo de la Gramática completa ${ }^{26}$, en los siguientes términos:

\section{Quid sit syntaxis, et in quot partes distribuatur.}

Syntaxis graece, latine constructio, est recta partium orationis inter se compositio. Porro recta compositio ea censenda est, qua usi sunt auctores, qui pure et emendate scripserunt. Haec duplex est. Altera transitiua, cum partes nimirum orationis in casum dissimilem praecendenti transeunt. Cic., ad Att., lib. 2: Pompeius amat nos carosque habet. Altera intransitiua, cum orationis partes aut nullum post se casum habent. Idem, ad Q. Fr., lib. 3: Valent pueri, studiose discunt, diligenter docentur. Aut certe non diuersum ab eo, qui antecessit. Idem, Philip. 3: Pax est tranquilla libertas. Vtraque in Iustam et Figuratam diuiditur [...]

De Figurata copiosius postremo loco dicendum est. Nunc a Iusta, eaque Intransitiua, quod facilior, expeditiorque sit, initium faciemus.

En la edición veneciana de 1570, al no contener escolios explicativos, no aparece el texto anterior. La edición mexicana de 1579 apenas contiene escolios explicativos, solo los preceptos generales, y quizá por eso I. Osorio $(1980,134)$ afirmó que correspondía a la edición veneciana de 1570. A partir de lo expresado por el editor en el prólogo, como veremos, consideramos que habría tenido más bien como referencia alguna de las ediciones individuales de la Sintaxis con escolios, previas a 1579, a la que incorpora la constructio figurata del libro segundo de la Gramática completa de Álvares, y a la que añaden sistemáticamente hexámetros mnemotécnicos.

\footnotetext{
25 Sobre la complejidad de la tradición textual de la sintaxis individual de Álvares en el siglo XVI, en Italia y spaña, $c f$. Ponce de León (2004).

26 En el libro segundo de la Gramática completa sí se tratará la sintaxis figurada, como veremos.
} 


\title{
4. Omisiones y adiciones resaltadas en el prólogo
}

Resulta evidente que la función principal del prólogo de cualquier obra es la presentación de la misma. Uno de los objetivos principales que se suele perseguir, en general, y, en concreto, en los prólogos de textos de corte didáctico como el que nos ocupa, es la legitimación de la obra, a menudo anticipando lo que se va a encontrar y resaltando y explicando el porqué de los elementos diferenciadores con respecto a otras anteriores o coetáneas. En este sentido, nuestro editor advierte de los cambios más relevantes sobre el que sería de uso común en Nueva España y de los motivos de estos; unos cambios que vendrían a apoyar, en parte, lo que ha sido adelantado: que esta edición fue realizada a partir de la veneciana (1571) o de la hispalense (1573); a fin de cuentas no varían en lo sustancial.

Pues bien, dos son los cambios fundamentales operados sobre la edición base y resaltados por el editor en el prólogo ${ }^{27}$. El primero es la omisión, por lo general, de los escolios explicativos, si bien es verdad que de estos se extraen algunas mínimas observaciones y ejemplos; se minimizaba así, en cierta medida, del carácter científico de la Gramática en pro de una marcada impronta pedagógica. El segundo es que se añade la sintaxis figurada. Pero veámoslo en el prólogo programático dedicado a los alumnos principiantes (ad tyrones):

\begin{abstract}
Ad tyrones
En uobis iterum foras datur (ingenui adolescentes) liber de octo partium orationis constructione, non illis quidem, quibus olim exierat explanationibus illustratus, diligentius tamen correctus, atque etiam auctus, adiecimus enim figuratam eiusdem autoris Sintaxim, quae, ne nimium uoluminis magnitudo excresceret, praetermissa tunc fuerat. Sustulimus itaque nunc praestantes illas explanationes, tum, ut huic Figuratae Sintaxi, uobis, ut credo, admodum profuturae, locus superesset, tum, ut tanta scholiorum multitudine sublata, minus impediremini. Quod si, praeter regulas, et appendices, addantur interdum obseruationes nonnullae ex ipsis scholiis desumptae, erunt sane quam breuissimae. Qui plura uolet, authoris adeat explicationes, vbi plurima reperiet lectu longe dignissima. Valete, et hoc nostrum ad uestra commoda studium boni consulite. (México 1579, f. A 2).
\end{abstract}

El editor presenta una nueva edición del De octo partium orationis constructione destinada a los jóvenes (En uobis iterum foras datur [ingenui adolescentes] liber de octo partium orationis constructione), sin los escolios explicativos con que se había publicado antes, pero, a cambio, corregida y aumentada (non illis quidem, quibus olim exierat explanationibus illustratus, diligentius tamen correctus, atque etiam auctus ), ya que en esta edición ha sido añadida la sintaxis figurada del propio autor, es decir, del propio Álvares (adiecimus enim figuratam eiusdem autoris Sintaxim), parte esta que se había omitido en una anterior edición en aras de que el libro no resultara demasiado extenso (quae, ne nimium uoluminis magnitudo excresceret, praetermissa tunc fuerat). Él, en cambio, opta por suprimir las explicaciones anteriores, por un lado, para dejar espacio a la sintaxis figurada, que, en su opinión, reportará

27 Veremos más adelante un tercer cambio que no aparece en el prólogo, la incorporación sistemática de versos mnemotécnicos, de lo que advierte en el comienzo mismo de los preceptos. 
a los estudiantes mucho provecho; por otro, para no dificultar el aprendizaje con tan gran cantidad de escolios (Sustulimus itaque nunc praestantes illas explanationes, tum, ut huic Figuratae Sintaxi, uobis, ut credo, admodum profuturae, locus superesset, tum, ut tanta scholiorum multitudine sublata, minus impediremini). No obstante, reconoce que, además de los preceptos, dispuestos en reglas generales y en apéndices, se han incluido algunos comentarios extraídos de los propios escolios, si bien estos serán lo más breves posibles (Quod si, praeter regulas, et appendices, addantur interdum obseruationes nonnullae ex ipsis scholiis desumptae, erunt sane quam breuissimae). En cualquier caso, a quien desee más información lo remite a los escolios explicativos del propio autor, en los que podrá encontrarse muchísimos contenidos dignos de lectura (Qui plura uolet, authoris adeat explicationes, vbi plurima reperiet lectu longe dignissima.) Finalmente, en la fórmula final de despedida, insta a los jóvenes a considerar que todo el esfuerzo realizado ha sido para beneficio de ellos (Valete, et hoc nostrum ad uestra commoda studium boni consulite).

Es decir, el editor parte de la existencia de una edición anterior que circularía y de la que podrían tener conocimiento los alumnos; una edición con escolios explicativos y a la que faltaban las figuras de construcción. Debe de tratarse, pues, de una edición del De octo partium orationis constructione bastante próxima a la rama de las publicadas en Venecia (1571, 1574), Sevilla (1573), Roma (1577), que coincidían, entre otros aspectos, en contener escolios explicativos y en carecer de la sintaxis figurada (Ponce de León 2004). Consideramos, pues, que puede descartarse la edición veneciana de 1570 , también perteneciente a la familia anterior y que coincidiría en carecer de la sintaxis figurada, pero esta no contiene escolios explicativos, como advierte su editor en el prólogo en forma de saludo al lector (LECTORI SALVTEM), solo los preceptos gramaticales de Álvares (Emanuelis) más necesarios, con unos pocos ejemplos, precisamente por estar destinada a los niños y a los novatos ${ }^{28}$. En cualquier caso, no es el cometido de este trabajo dilucidar qué edición concreta pudo tomar como base. Ello quedará para un trabajo futuro.

\subsection{Omisión de escolios}

En cuanto a los escolios o explanationes, es sabido que en las versiones maiores de la Gramática de Álvares, desde las primeras ediciones individuales de la Sintaxis (Venecia 1571 y Sevilla 1573), se diferencian incluso tipográficamente de los preceptos generales, apéndices y excepciones. La Gramática de Álvares cumpliría con las dos secciones que, según Quintiliano (Inst.1.9.1), debía abarcar el oficio del gramático: methodice e historice. Con los preceptos generales, destinados a todos los alumnos, se perseguiría un dominio oral y escrito correcto de la lengua latina, atendiendo así a la vertiente methodice de la Gramática. En los escolios explicativos se encontraban los usos más elegantes de la lengua latina y proporcionaban una serie de recursos pedagógicos en materia de exégesis y metodología que pudieran aprovecharse para cumplir con la sección historice de la gramática, basada en la interpretación de los autores. Estarían destinados a los alumnos de niveles superiores y, sobre todo, a los maestros. En estos escolios Álvares introducía opiniones y reflexiones lingüísticas propias y de otros autores, comentarios estilísticos sobre la mayor o menor elegancia

28 Venecia 1570: [...] propterea nos in usum puerorum ac rudium, Emanuelis ipsa dumtaxat praecepta grammatices maxime necessaria paucis adscriptis exemplis, in praesentia emittimus. 
de determinadas construcciones, comentarios sobre la etimología de ciertos términos, de crítica textual, etc. Son unas explicaciones que se suprimen, por lo general, en las ediciones abreviadas, destinadas a los alumnos, a quienes interesa un primer contacto breve y claro con la lengua latina. Así lo hace y así hemos visto que lo indica en el prólogo el editor novohispano, en el mismo sentido que se indicaba en la veneciana de 1570 .

No obstante, también se advierte en el prólogo que se añade en esta edición alguna información de los escolios de ediciones anteriores, pero muy breve: Quod si, praeter regulas, et appendices, addantur interdum obseruationes nonnullae ex ipsis scholiis desumptae, erunt sane quam breuissimae. Así sucede, por ejemplo, con la inclusión de los diez relativos denominados «de accidente», que se encuentran en uno de los escolios de los relativos:

Decem sunt, quae relatiua accidentis vocant, Quantus, Qualis, Quot, Quotus, Quoteni, Quotuplus, Qualis, Quot, Quotus, Quoteni, Quotuplus, Quotuplex, Quotenis, Cuius, $a$, um, Cuias, quorum exceptis primis duobus, fere, quod rem attinet, nullus est vsus. (México 1579, f. 5vº; Venecia 1571, f. 7 ro; Lisboa 1572, f. 113r ${ }^{\text {o }}$; Sevilla 1573, f. $11 r^{\circ}$; Roma 1577, f. $\left.10 r^{\circ}\right)$.

O con la inclusión de los verbos llamados «vocativos» que aparece dentro del epígrafe Vtrinque nominandi casus: Vocatiua uerba uocant Appellor, Vocor, Nuncupor, Nominor, Dicor, et si qua sunt de eodem genera (México 1579, 6v $\mathrm{v}^{\mathrm{0}}$; Venecia 1571, f. $9 \mathrm{v}^{\mathrm{o}}$; Lisboa 1572 , f. $114 \mathrm{v}^{\mathrm{o}}$, Sevilla 1573 , ff. $13 \mathrm{v}^{\mathrm{o}}-14 \mathrm{r}^{\circ}$; Roma, $1577,12 \mathrm{v}^{\circ}$ ).

$\mathrm{O}$, por poner un último ejemplo, si bien hay más a lo largo de obra, lo mismo sucede con la inclusión de los que son propiamente adjetivos partitivos, ordenados alfabéticamente, como estaban en los escolios de las otras ediciones:

Partitiua uocamus, quae maxime partitiua sunt ut Alius, Aliquis, Alter, Alteruter, Nemo, Neuter, Nullus, Quis, Quicumque, Quidam, Quilibet, Quisquis, Quiuis, Quispiam, Quisquam, Quisque, Solus, Vllus, Vnusquisque, Vter, Vterque, Vtercumque, Vterlibet, Vteruis. (México 1579, f. 9v 1572, f. $118 \mathrm{v}^{\mathrm{o}}$; Sevilla 1573 , f. $21 \mathrm{r}^{\mathrm{o}}$; Roma, 1577 , f. $17 \mathrm{r}^{\circ}$ ).

Basten como ejemplo estos pasajes. Se trata de fragmentos que se hallaban en los escolios de las ediciones referidas, no en los preceptos generales, $\mathrm{y}$, de hecho, en las ediciones minores -solo con los preceptos generales-, como la de Venecia (1570) -solo el De constructione- o Lisboa (1573 y 1578) -con los tres libros-, no aparecen estos pasajes. Es evidente que el editor consideraría importante incluir esta información procedente de los escolios del propio autor, del propio Álvares, en un manual básico para el correcto entendimiento y dominio de la lengua latina, como también considera pertinente la inclusión de las figuras de construcción.

\subsection{Adición de la Sintaxis figurada}

La adición de la Sintaxis figurada es el segundo de los cambios mencionados en el prólogo. El editor novohispano añade la Sintaxis figurada de alguna edición del propio Álvares: ... adiecimus enim figuratam eiusdem autoris Sintaxim. 
En efecto, desde Linacro, con su De emendata structura Latini sermonis libri sex (Londres 1524; edición moderna: Harto 1998), se venía aceptando en el análisis sintáctico la distinción entre la constructio o syntaxis iusta o propria y la constructio figurata $^{29}$. El autor inglés consideraba las figuras de construcción un mecanismo básico en la explicación gramatical al estar presentes en gran parte de las realizaciones de la lengua latina y, sin ellas, se podía grammatice loqui pero no latine loqui. Álvares, en la línea de la moderna tradición gramatical europea de la gramática racional y siguiendo muy de cerca a Linacro, se sumó a esta tendencia desarrollando el estudio de las figuras en el último capítulo del libro segundo de su Gramática completa (Lisboa 1572) y manteniendo los preceptos generales de la construtio figurata en las ediciones completas subsiguientes abreviadas (Lisboa 1573 y 1578). Serán los preceptos generales de Álvares lo que incorpore el editor novohispano básicamente. Solo cabría hacer al respecto dos puntualizaciones.

La primera es que encontramos un caso en el que incorpora contenido de uno de los escolios explicativos que se hallaban únicamente en las ediciones extensas (maiores) de la Gramática de Álvares: así sucede al tratar del zeugma. Tras el precepto general, precedido de su correspondiente hexámetro mnemotécnico añadido por el editor novohispano, se incorpora también parte del escolio en que enumeraban los tipos de zeugma. Reproduzco el contenido íntegro del pasaje con espacio entre verso mnemotécnico, precepto general con ejemplos y escolio con ejemplos:

\section{ZEVGMA.}

Quod deest in simili desumit zeugma propinquo.

Zeugma figura est, cum id, quod in oratione desideratur, e proximo assumitur, manente eodem genere, numero, casu, caeterisque atributis $<$ sic $>$. Cic. Nulla possessio, nulla uis auri pluris, quam uirtus, aestimanda est. Idem. Virtus, et honestas, et pudor cum Consulibus esse cogebat.

Si id, quod assumitur ad orationem implendam, primum est, Protozeugma dicitur. Cic. Ad Att. lib. 16. Egit pater, et filius, ut tibi responderem. Si medium, Mesozeugma. Autor ad Heren. Formae dignitas, aut morbo deflorescit, aut uetustate. Si postremum, Hypozeugma. Cic. ad Att. lib. 12. Mihi et res et conditio placet. $\left(\text { México } 1579,51 v^{\mathrm{o}}\right)^{30}$.

La segunda puntualización tiene que ver con el siguiente punto que trataremos; en concreto, con el contenido del último hexámetro mnemotécnico que añade el editor, y que, por tanto, será también el verso que cierre la lista de hexámetros recopilatorios de la que hablamos en la descripción del volumen. Este último verso se encuentra en la prolepsis, antes del precepto general del original de Álvares. Como en el caso anterior, reproducimos el pasaje con separación entre los versos añadidos y el precepto general original con alguno de sus ejemplos:

29 En general, para el tratamiento de las figuras de construcción en la gramática latina, con capítulos dedicados específicamente al tratamiento que de las mismas hace Manuel Álvares, cf. Colombat (1993, 210-217) y Sánchez (2002, 561-564). Además, concretamente sobre la modernidad en el tratamiento de la Sintaxis por parte del Padre Álvares, $c f$. Mañas (1999); Gómez (2000); Ponce de León (2002, CXLII-CLII); Sánchez (2004).

30 Esta parte del escolio ( $S i$ id, ... placet), en los mismos términos, se encuentra en el folio $189 \mathrm{v}^{\circ}$ de la edición de 


\section{PROLEPSIS.}

Quod prius est dictum supplet reticendo prolepsis.

\section{Caetera Rethoricis $<s i c\rangle$, habet hic constructionem finem.}

Prolepsis est, cum dictio aliqua totum significans praecessit, quae rursus in partibus intelligitur, neque explicatur. Vt Duo reges Romam auxerunt, Romulus belo, Numa pace. [...] (México 1579, f. $52 \mathrm{r}^{\circ}$ y $60 \mathrm{v}^{\circ}$ ).

A juzgar por su contenido, el editor parece querer dejar clara constancia de que la prolepsis era la última figura que debía considerarse específicamente gramatical y que, por tanto, ahí acabaría la constructio figurata, y, con ella, la Sintaxis (habet hic constructionem finem). Así, las figuras que considera propiamente gramaticales son la enálage, la elipsis, el zeugma, la silepsis y la prolepsis, que son las tratadas hasta ahí; todo lo que que viene a continuación (caetera), es decir, el resto de figuras (arcaísmo y helenismo), el barbarismo (defecto que afecta a una sola palabra y no a una oración) y el resto de defectos que hacen que la oración sea oscura (el hipérbaton con sus distintos tipos) y carente de ornato, que incluía Manuel Álvares en su Sintaxis figurada -y que presentará él, pues ya hemos dicho que incorpora íntegramente el texto de los preceptos generales del jesuita portugués-sería, en su opinión, cometido de los rétores (caetera rethoris $<$ sic $>$ ).

Ya se ha dicho en otra ocasión que Manuel Álvares realizaba un tratamiento de la Sintaxis figurada a medio camino entre la Gramática y la Retórica (Gómez 2000); en ese sentido, en ocasiones, daba la impresión de considerar alguna figura más como figura ornatus que como figura constructionis, tal y como sucedía, por ejemplo, con el hipérbaton (Sánchez 2004, 55): Cum orationis structura decoris gratia uariatur, neglecto simplici sermonis ordine, non uitium est, sed uirtus, quae Hyperbaton appellatur, id est, transgressio uerborum (México 1579, f. 54vo ; Lisboa 1572, f. 194vº) ${ }^{31}$. Pues bien, creemos que el editor novohispano, con la inclusión de su hexámetro, pretendió establecer nítidamente esa diferenciación entre las figuras propiamente de construcción, que afectarían a la corrección de la oración y que correspondería tratarlas al gramático, y aquellas otras palabras, construcciones y defectos que tendrían más que ver con la propiedad en el uso de la lengua latina, con la claridad y la elegancia, y que serían cometido de los rétores. De hecho, no añade versos en el encabezamiento del arcaísmo, del helenismo o del barbarismo; ni delante de los defectos que hacen que la oración sea oscura, como el hipérbaton y sus tipos; ni delante de los defectos que hacen que la oración carezca de ornato. Y, como consecuencia de ello, tampoco en el apéndice recopilatorio final con los versos distribuidos a lo largo de la edición. El cometido de este apéndice sería contribuir a la memorización de los conceptos mediante la repetición de los mismos; no le parecería fundamental al editor novohispano que los alumnos debieran memorizar unos conceptos que pertenecerían más al ámbito de la Retórica que al de la Gramática.

Por otra parte, y volviendo a la justificación del editor en el prólogo en cuanto a la omisión de explicaciones y ejemplos para dejar espacio para las figuras de cons-

Lisboa 1572

31 Cuando la estructura de la oración se cambia para dar mayor ornato, aunque se descuide el orden natural de la lengua, no se trata de un defecto, sino de un detalle de elegancia que recibe el nombre de «hipérbaton», esto es, alteración de orden de palabras. Cf. Gómez (2003, 348). 
trucción, cabe plantearse el sentido de la misma; Álvares no justificaba la inclusión de las figuras de construcción en la editio princeps de su De institutione grammatica libri tres, con escolios; pero es que tampoco se justificaba en las ediciones minores (Lisboa 1573 y 1578) la supresión de ejemplos y escolios explicativos para dejar espacio a la Sintaxis figurada; solo lamentaba, en el prefacio (Auctor lectori), haber tenido que quitar los escolios para facilitar a los estudiantes el acceso a la obra (Kemmler 2013, 47-48). La respuesta primera y más simple a esta cuestión parece obvia y ya ha quedado expuesta con anterioridad. El editor novohispano no estaría trabajando sobre la gramática completa -la más extendida en Europa en sus versiones maiores y minores- sino sobre la versión del De constructione que se tuviera de uso en Nueva España, y esta no contenía las figuras de construcción; de otro modo no tendría explicación que mencionara su añadido en el prólogo; pero al tiempo tiene conocimiento de la versión completa europea y juzga oportuno incorporar este apartado. No obstante, además, creemos que puede haber otra razón: que tampoco estaba el tratamiento de la constructio figurata en la Gramática de Maturino, -recordemos que fue impresa en México en 1559 que gozó de gran importancia (Osorio 1980 y 1984) -. Quizá también por ello, para reivindicar un valor añadido en su edición sobre la del franciscano, un valor añadido que resultaría muy beneficioso para los jóvenes, resaltaba la adición de la Sintaxis figurada en el prólogo. En cualquier caso, parece consciente el editor novohispano de que el conocimiento de tales estructuras resultaba necesario para un dominio correcto y elegante de la lengua latina, como se era ya consciente de ello en Europa, y así lo señala en la presentación de la obra.

\subsection{Inclusión sistemática de versos mnemotécnicos}

Como se ha ido adelantando a lo largo del trabajo, hay otra novedad con respecto a las ediciones anteriores del De constructione que resulta digna de comentario: la adición sistemática de versos mnemotécnicos.

Se trata, como es sabido, de un recurso de tradición medieval. El Doctrinale de Alejandro de Villadei (1199) o el Graecismus de Everardo de Bethune (1212), por ejemplo, habían sido escritos en verso y habían influido en las gramáticas bajomedievales (Cuadra 2009). Posteriormente, en el siglo XV, Guarino de Verona en sus Regulae grammaticales (1417) o Nebrija en sus Introductiones los utilizarán también, en ocasiones, en sus gramáticas. Concretamente Nebrija, en el libro segundo de Introductiones Latinae, en su versión de 1495, había puesto las reglas generales de los géneros de los nombres y de los perfectos y supinos en hexámetros, para a continuación explicarlas en extensos comentarios. El propio Manuel Álvares los utilizó en las mismas partes del libro primero de su De institutione grammatica libri tres (Lisboa 1572) y solo esporádicamente en la Sintaxis y en la Prosodia ${ }^{32}$. Con posterioridad, otros dos gramáticos jesuitas, los autores de las reformas más difundidas de la Gramática de Álvares, el italiano Horacio Torsellino y el portugués Antonio Vélez, ampliaron el número de versos mnemotécnicos en sus reformas. Torsellino $\left(\right.$ Roma 1584) ${ }^{33}$, por ejemplo, los incorporó a lo largo de todo el tercer libro (Prosodia

\footnotetext{
32 Álvares, al tratar los géneros de los nombres (Lisboa 1572, ff. 63v $\mathrm{v}^{\mathrm{o}}-77 \mathrm{v}^{\mathrm{o}}$ ), en los perfectos y los supinos (ff. $\left.94 \mathrm{r}^{\circ}-107 \mathrm{v}^{\mathrm{o}}\right)$.

33 Torsellino, O. (1584), Emmanuelis Alvari e Societate Iesu, De institutione Grammatica libri tres. Quorum se-
} 
y Métrica). Vélez (Évora 1599) ${ }^{34}$, puntualmente en la Morfología y de forma sistemática a lo largo de toda la Sintaxis -del mismo modo que lo había hecho ya en 1579 el editor novohispano, aunque no se tratara de los mismos versos- y en la Prosodia y la Métrica (Springhetti 1962, 292-7). Precisamente, los versos mnemotécnicos se convertirían desde muy pronto en objeto de elogio o de crítica respectivamente entre los defensores y detractores de la Gramática alvaresiana ${ }^{35}$.

De todos modos, lo que nos interesa aquí es el hecho de que habría que adelantar esa incorporación sistemática de versos mnemotécnicos en la Sintaxis de Álvares a la edición que estamos estudiando. El modo de incorporación de los versos era ya conocido en la tradición gramatical: en unos pocos versos expone el precepto, a continuación se expone en prosa y se desarrolla con los ejemplos oportunos. Valgan como ejemplo los textos anteriores del zeugma y la prolepsis.

Pero es que, además, el editor novohispano no se conforma con incluirlos al comienzo de cada precepto general, excluidos los apartados mencionados ${ }^{36}$, sino que los recopila todos juntos al final, ff. $56 \mathrm{v}^{\mathrm{o}}-60 \mathrm{v}^{\circ}:$ R. P. EMANVELIS ALVARI SOCIETATIS Iesu. Carmine breuite collecta. De nuevo estamos ante un procedimiento muy medieval. Resulta evidente que consideraría productiva la recurrencia a este tipo de versos en la enseñanza de la gramática, $\mathrm{y}$, si bien no advierte de su incorporación en el prólogo, sí lo hace y justifica su uso -precisamente con hexámetros mnemotécnicos- en el propio comienzo, sin definir ni siquiera lo que es la Sintaxis. No deja de ser relevante que el editor considere más importante justificar el uso de versos para facilitar la memorización que definir en qué consiste la Sintaxis.

Así, la «sintaxis», denominación que los griegos dan a lo que los latinos llaman «construcción», se presenta adornada en metros rítmicos -aludiría a los versos que encabezan cada precepto- y se resume en unos cuantos versos -la recopilación de versos final- para que la mente pueda retener los contenidos dispersos a lo largo de la obra y no se vea abrumada por la multitud de los mismos:

\author{
DE OCTO PARTIVM ORATIONIS CONSTRVCTIONE LIBELLVS ${ }^{37}$. \\ De constructione intransitiua. \\ Nominatiuus et Verbum. \\ Quod sit sintaxis. \\ Sintaxis graecis constructio dicta Latinis, \\ In numeris uariata modis, in carmina pauca \\ Ducitur, vt fuse quae commentaria traddunt \\ Mens retinere queat nec magna mole grauetur. (México 1579, f. 2vº).
}

cundus nuper est ad Veterum fere Grammaticorum rationem reuocatus. Romae: Apud Franciscum Zanettum.

34 Vélez, A. (1599), Emmanuelis Alvari e Societate Iesu De Institutione Grammatica libri tres, Antonii Vellesii ex eadem Societate Iesu in Eborensi Academia Praefecti Studiorum opera aucti et illustrati, Eborae: Excudebat Emmanuel de Lyra Typographus. Precisamente Vélez, en el prólogo de su reforma, hará una contundente defensa de la utilización de versos mnemotécnicos, como hemos estudiado en un trabajo de inminente publicación.

35 Sobre las polémicas en torno a la Gramática de Álvares, $c f$. Springhetti (1962, 291-302) y Ponce de León (2002, LXXXIX-XCVII).

36 No añade versos al frente de las partes indeclinables ni en las partes de la constructio figurata cuyo tratamiento consideraría más propio de los rétores.

37 El título del comienzo es diferente del de la portada, De constructione octo partium orationis, como también difería en las ediciones anteriores: Venecia 1571 y Sevilla 1573. La veneciana de 1570 no lleva este título; comienza directamente la doctrina con el encabezamiento DE CONSTRVCTIONE INTRANSITIVA. 


\section{Conclusión}

Como se planteaba al inicio de este trabajo, se ha procurado dar cuenta de las modificaciones más relevantes que presenta esta edición del De octo partium orationis constructione (México 1579) con respecto a ediciones individuales anteriores de este mismo tratado sintáctico (Venecia 1570 y 1571, y Sevilla 1573, fundamentalmente), pero también con respecto al libro segundo de su Gramática completa en sus versiones amplias (Lisboa 1572) y abreviadas (Lisboa 1573 y 1578), que se debieron de tener en cuenta para la incorporación de la Sintaxis figurada.

En cuanto al volumen completo en el que se encuentra el De constructione octo partium orationis, se ha destacado la inclusión de un capítulo de Copia uerborum, que respondería a las exigencias de la pedagogía gramatical jesuita, en la línea de ofrecer a los alumnos un conjunto de expresiones variadas de las que poder hacer uso en la vida cotidiana de cara a un dominio oral y escrito, correcto y elegante de la lengua latina. Habría que adelantar, pues, la incorporación de este capítulo independiente de Copia uerborum vinculado con la Sintaxis de Álvares a la fecha de esta edición novohispana.

Una segunda novedad importante estaba relacionada con las figuras de construcción, que no se hallarían en la edición de la que se parte, pero sí se encontraban en el libro segundo de las versiones europeas de la Gramática completa de Álvares, de donde se toma este capítulo. El editor novohispano, consciente del valor que reportaría el conocimiento de estos mecanismos del lenguaje para un dominio correcto y elegante de la lengua latina desde los primeros niveles de enseñanza, juzgó conveniente destacar su importancia desde el prólogo. Pero es que, además, se produce una innovación incluso con respecto a las versiones Europeas de la Gramática completa, pues el editor divide las figuras de Álvares en figuras gramaticales y figuras retóricas, división que no había planteado explícitamente el autor portugués, ni conocemos edición del De institutione en que se plantee anterior a esta de 1579.

Una última novedad importante que hemos visto es la presencia reiterada de hexámetros mnemotécnicos; unos hexámetros que primero presentan los preceptos generales y después los recapitulan para facilitar su memorización y su fijación en la mente durante más tiempo. Si bien el editor novohispano no informa de esta novedad y de su razón de ser en el prólogo, sí lo advierte en el inicio mismo de la doctrina. Como en los casos anteriores, habría que adelantar también a esta edición la inclusión sistemática de versos mnemotécnicos en la Sintaxis de Álvares.

En definitiva, consideramos que el volumen dado a la luz en el Colegio de los jesuitas de San Pedro y San Pablo, en Nueva España, construido a partir de la Sintaxis individual de Álvares, constituye un ejemplo significativo del método jesuita de enseñanza de la Gramática latina, apoyado en continuas repeticiones de los preceptos bajo distintas formas y con construcciones prácticas en pro de un correcto y elegante dominio de la lengua latina; y todo ello combinando recursos y material pedagógico de la tradición gramatical europea bajomedieval y del primer humanismo (versos mnemotécnicos y capítulo de Copia uerborum), con el tratamiento de elementos propios de la moderna Gramática racional europea, como las figuras de construcción. 


\section{Referencias bibliográficas}

Álvares, M. (1571 [1570]), De constructione octo partium orationis. Emanuelis Alvaris Lusitani e Societate Iesu libellus. Nunc primum in lucem editus. Venetiis, apud Michaelem Tramezinum. Anno post Christum natum. MDLXXI. Cum priuilegio Pont. Max. Senatus Veneti, et Regni Neapolitani. [MDLXX en el colofón]. <https://books.google.pt/books?i$\mathrm{d}=$ OeMZI7z3AbYC $>$ [25/04/2017] (=Venecia 1570).

Álvares, M. (1571), De constructione octo partium orationis liber Emanuelis Alvari Lusitani e Societate Iesu liber. Cum explicationibus auctoris eiusdem. Cum priuilegio Summi Pontificis, et illustriss. Senatus Veneti ad annos XX. Necnon Illustriss. Proregis Regni Neapolitani. (Venetiis, apud Michaelem Tramezinum. MDLXXI, en el colofón). Edición digitalizada a partir del ejemplar de la Biblioteca Nacional Central de Roma <https:// books.google.es/books?id=8s0InNzk8NUC> [25/04/2017]. (=Venecia 1571).

Álvares, M. (1572), Emmanuelis Alvari e Societate Iesu De institutione grammatica libri tres, Olypssippone, excudebat Ioannes Barrerius. (Ed. facs. J. Pereira da Costa, Funchal, 1974). Edición digitalizada a partir del ejemplar de la Biblioteca Histórica de la Universidad Complutense de Madrid <https://books.google.es/books?id=cYcLaL5F_YcC $>$ (=Lisboa 1572).

Álvares, M. (1573), De constructione octo partium orationis liber Emanuelis Aluari Lusitani e Societate Iesu. Cum explicationibus auctoris eiusdem, Hispali, apud Alfonsum Scribanum via Serpentina. Edición digitalizada a partir del ejemplar de la Biblioteca Histórica de la Universidad Complutense de Madrid < https://books.google.es/books?id=QQimcG9_h8cC> [25/04/2017]. (= Sevilla 1573).

Álvares, M. (1573), Emmanuelis Alvari e Societate Iesu De institutione grammatica libri tres, Olyssippone, Excudebat Ioannes Barrerius, Typographus Regius. Edición de la Biblioteca Geral da Universidade de Coimbra (Sign. V.T.-18-7-3) (=Lisboa 1573).

Álvares, M. (1574), De constructione octo partium orationis liber Emanuelis Aluari Lusitani e Societate Iesu. Cum explicationibus auctoris eiusdem, Cum priuilegio Summi Pontificis, et Illustriss. Senatus Veneti ad annos XX. [Venetiis, Apud Michaelem Tramezinum MDLXXIIII, en colofón]. Edición digitalizada a partir del ejemplar de la Biblioteca Nacional Central de Roma <https://books.google.es/books?id=f3UiH-qj7BwC $>$ [25/04/2017]. (=Venecia 1574).

Álvares, M. (1577), De constructione octo partium orationis liber Emanuelis Aluari Lusitani e Societate Iesu. Cum explicationibus auctoris eiusdem, Cum priuilegio Summi Pontificis, et Illustriss. Senatus Veneti ad annos XX. El cum licentia Superiorum. Romae, Impensis haeredum Francisci Tramezini. Apud Iosephum de Angelis. Edición digitalizada a partir del ejemplar de la Biblioteca universitaria Alessandrina (Roma) <https://books. google.es/books?id=TcbKZiGLpr4C $>$ [25/04/2017]. (=Roma 1577).

Alvares, M. (1578), Emmanuelis Alvari e Societate Iesu De institutione grammatica libri tres, Olyssippone, Excudebat Ioannes Barrrius, expensis Ioannis Hispani Bibliopolae Typographus Regius. Edición digitalizada a partir del ejemplar la Biblioteca Histórica de la Universidad Complutense de Madrid <https://books.google.es/books?id=5qXtjfWn1s$\mathrm{kC}>[25 / 05 / 2017]$. (=Lisboa 1578).

Álvares, M. (1579), De constructione octo partium orationis. P. Emanuelis Aluari Lusitani e Societate Iesu, Mexici, Cum licencia, Apud Antonium Ricardum. Edición digitalizada a partir del ejemplar de la University Library de Texas <http://hdl.handle.net/1969.1/92820> [25/05/2017]. (=México 1579).

Álvares, M. (1593), De constructione octo partium orationis liber. Emanuelis Alvari, Lusitani, e Societate Iesu, Madriti, Ex officina Petri Madrigalis. Edición digitalizada a partir 
del ejemplar la Biblioteca Histórica de la Universidad Complutense de Madrid $<$ https:// books.google.es/books?id=KBpYSwiR870C $>$ [25/04/2017]. (=Madrid 1593).

Codina Mir, G., S.I. (1968), Aux sources de la pédagogie des jésuites. Le «modus parisiensis», Roma, Institutum Historicum S. I.

Colombat, B. (1993), Les figures de construction dans la syntaxe latine (1500-1780); Lovaina - París, Editions Peeters.

Cuadra García, F. (2009), «Los versos mnemotécnicos en los tratados de ortografía latina de la Baja Edad Media», CFC (L) 29,1, 117-139.

Espino Martín, J. (2005), Evolución de la enseñanza gramatical jesuitica en el contexto socio-cultural español entre los siglos XVI y primera mitad del XVIII, Madrid, Universidad Complutense de Madrid. <http://biblioteca.ucm.es/tesis/fll/ucm-t28425.pdf> [27/04/2017]

Fernández, E. M. (1994), «El libro en Hispanoamérica» en Escolar, H. (dir.), De los incunables al siglo XVIII, Madrid, Fundación Germán Sánchez Ruipérez, 447-497.

Gómez Gómez, J. M.a (2000), «La figura de construcción en la Gramática de Manuel Álvares. Un planteamiento lingüístico-retórico», Anuario de Estudios Filológicos, 23, 187-204.

Gomez Gómez, J. M. a (2003 [1572]), Emmanuelis Alvari e Societate Iesv De Institutione Grammatica liber secundus, De octo partium orationis constructione. Estudio, edición crítica, traducción, notas e índices. Cáceres, Universidad de Extremadura. <https://dialnet.unirioja.es/servlet/tesis?codigo=27062> [25/04/2017].

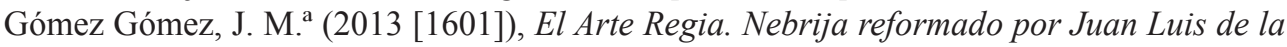
Cerda. Morfología y Sintaxis. Introducción, edición crítica, traducción y notas, Cáceres - Alcañiz, Servicio de Publicaciones de la Universidad de Extremadura - Instituto de Estudios Humanísticos.

Gómez Robledo, X. (1954), Humanismo en México en el siglo XVI. El sistema del colegio de San Pedro y San Pablo, México, Editorial Jus.

Gonzalbo Aizpuru, P. (1989), La educación popular de los jesuitas, México, Universidad Iberoamericana.

Harto Trujillo, M. ${ }^{a}$ L. (1998 [1524]), Thomas Linacer. De emendata structura Latini sermonis. Introducción, edición crítica, traducción y notas, Cáceres, Universidad de Extremadura.

Kemmler, R. (2013), «De institutione grammatica libri tres (Lisboa, 1573): a edição princeps da ars minor de Manuel Álvares», Revista Portuguesa de Humanidades. Estudos Linguísticos, 17, 1, 43-58.

León, N. (1887), Un impreso mexicano del siglo XVI. Nota bibliográfica Núm. 1, Morelia.

Lucas, R. (2003 [1559]), Grammatica Maturini. Introducción, edición, traducción y notas, México, El Colegio de Michoacán.

LUSODAT. Grupo de História, Teoria e Ensino de Ciências (GHTC) de la Universidade de São Paulo, USP. «Padre Manuel Álvares - Gramática - edições completas ou parciais». $<$ http://www.ghtc.usp.br/server/Lusodat/pri/02/pri02145.htm> [10/04/2017].

Mañas Núñez, M. (1999), «Aproximación a la sintaxis latina de Manuel Álvares», en Melo, A. M. ${ }^{a}$ (coord.) Actas do I Congresso Internacional do Humanismo Novilatino e Pedagogia (Gramáticas, Criações Maiores e Teatro), Braga, Centro de Estudos Clássicos da Faculdade de Filosofía - UCP, 237-249.

Medina, J. T. (1989 [facs. 1912]), La imprenta en México, (1539-1600), t. 1, núm. 87 México, UNAM, Coordinación de Humanidades, 236-237.

Osorio Romero, I. (1979), Colegios y profesores jesuitas que enseñaron latín en Nueva España (1572-1767), México, UNAM: IIFL: CEC (Cuadernos del Centro de Estudios Clásicos, 8). 
Osorio Romero, I. (1980), Floresta de gramática, poética y retórica en Nueva España (15211767), México, UNAM: IIFL: CEC (Cuadernos del Centro de Estudios Clásicos, 9).

Osorio Romero, I. (1984), «Tres joyas bibliográficas para la enseñanza del latín en el siglo XVI novohispano», Nova Tellus, 2, 164-200.

Osorio Romero, I. (1990), La enseñanza del latín a los indios, México, UNAM.

Palau y Dulcet, A. (1948, t. I), Manual del librero hispano-americano, Barcelona, Librería anticuaria de A. Palau.

Pérez Luna, J. A. (2009), «Latín y educación superior. Un texto de enseñanza del siglo XVI novohispano», Diario de campo, 104, 50-56. <https://revistas.inah.gob.mx/index.php/ diariodecampo/article/view/7734/8596> [25/04/2017]

Ponce de León Romeo, R. (2002 [1572]). Aproximación a la obra de Manuel Álvares: edición crítica de sus De institutione grammatica libri tres, Madrid. Universidad Complutense de Madrid. <http://eprints.ucm.es/tesis/fll/ucm-t25106.pdf> [25/04/2017].

Ponce de León Romeo, R. (2003), «El Liber de octo partium orationis constructione (Medina del Campo, 1600) de Bartolomé Bravo, S. I., y sus comentadores durante los siglos XVII y XVIII», Revista da Faculdade de Letras - Línguas e Literaturas, II série, 20, 569-606.

Ponce de León Romeo, R. (2004), «Notas sobre la tradición textual del De constructione octo partium orationis (Venecia, 1570) de Manuel Álvares, S. I., en Italia y en Castilla durante el siglo XVI», Revista da Faculdade de Letras - Linguas e Literaturas, II série, 21, 269-285.

Sánchez Salor, E. (2002), De las “elegancias" a las "causas" de la lengua: retórica y gramática del humanismo, Alcañiz - Madrid, Instituto de Estudios Humanísticos - C.S.I.C.

Sánchez Salor, E. (2004), «La modernidad de la Gramática del Padre Álvares», Revista Portuguesa de Humanidades 8, 27-57.

Sánchez Salor, E. (2012), La Gramática en Europa durante el siglo XVII. Dispersión doctrinal, Alcañiz - Madrid, Instituto de Estudios Humanísticos - C.S.I.C.

Sommervogel, C., S.J. (1890, t. I,), Bibliothèque de la Compagnie de Jésus, Bruselas - París, Picard.

Springhetti, E., S. I. (1962), «Storia e fortuna della Grammatica di Emmanuele Alvares, S. J.», Humanitas 13-14, 283-303.

Valencia Constantino, G. (2015), «El estudio de las elegancias latinas en Nueva España», Filologías. Revista de novedades críticas. Enero - abril, 1-19. 